\title{
Prenumele diminutivate între SaCru și Profan
}

\author{
Silvia Iluț \\ Universitatea Tehnică din Cluj-Napoca, \\ Centrul Universitar Nord Baia Mare, România
}

\section{Diminutive first names between sacred and profane}

\begin{abstract}
The first name defines the identity of a person and is one of the elements through which a person is recognized and singled out in the community to which he or she belongs. The origin of first names is closely related to the act of christening, through which all the functions of a name are subsequently validated.

The present study aims to identify the psycho-affective motivations which determine the modification of the primary form of a first name, in our case, the transition to a diminutive. The study relies on a comparative analysis of the principles through which names are attributed in secular society and the onomastic particularities of the monastic world.

In order to illustrate the aforementioned aspects, the study begins with the classification of first names into two large categories: secular and related to the calendar (with an obvious religious connotation), in addition to derivative and hypocoristic forms. If secular first names (Lăcrimioara, Mioara) are only given to laypeople, forenames with religious connotation are present in both communities. The difference is that religious forenames may appear in secular society as derivative forms or hypocoristics (Gheorghiță, Ghiță), while in the monastic milieu only primary forms are used (Filofteia, Iustin). In this "confined" space, diminutive forenames are perceived as inappropriate in relation to the idea of consecration and religiousness. However, in the secular world, the sacred aspect of first names is also present in diminutive forms, as the name giver refers to the sacred in the act of naming, thereby conferring spiritual meaning to first names.

The methodology of this study is specific to onomastics, psycholinguistics and pragmatics. The corpus of the paper consists of the results of a sociolinguistic survey, as well as results and opinions gathered by means of well-documented internet research.
\end{abstract}

Keywords: diminutive, first name, sacred, psycholinguistics, psychosocial.

\section{Considerații preliminare}

Prezenta lucrare își propune să identifice motivațiile psihoafective care determină modificarea formei de bază a unui prenume, în cazul nostru trecerea la un diminutiv. Cercetarea se bazează pe o analiză comparativă între criteriile după care se atribuie prenumele în lumea laică și particularitățile denominative din lumea monahală.

Suportul teoretic îl constituie cadrul onomasticii, acesta apelând și la principiile 
pragmaticii și ale semioticii. De asemenea, studiul are în vedere metodele și principiile teoretice ale psiholingvisticii și sociolingvisticii, evidențiindu-se mecanismele cognitive și afective care influențează utilizarea prenumelor diminutivate. Corpusul este constituit prin intermediul anchetei sociolingvistice și din exemple extrase din internet. Studiul vizează prenumele laice și numele monahale din mănăstirile și schiturile ortodoxe din județul Maramureș, România.

\section{Considerații teoretice}

\subsection{Prenumele}

Pornind de la premisa că prenumele definește identitatea ${ }^{1}$ persoanei, fiind unul din elementele prin care aceasta este recunoscută și individualizată ${ }^{2}$ in comunitatea din care face parte, ne propunem să investigăm modalitățile de numire ${ }^{3}$ din cele două spații, lumea laică / monahală, din perspectivă comparativă.

Orice ființă umană este unică în specificitatea ei, deoarece posedă un prenume care o individualizează de ceilalți indivizi în cadrul familiei sau al comunității. Numele oricărei persoane dobândește un cumul de caracteristici și provoacă o imagine în iconografia mentalului celui care îl pronunță. Potrivit Dicționarului explicativ al limbii române, prenumele reprezintă un „nume care se dă unui om la naștere și care distinge pe fiecare dintre membrii aceleiași familii”. Conform Daianei Felecan (2013: 761), „a da nume unei persoane implică o primă etapă a numirii, treapta clasificatoare, să-i spunem, individului fiindu-i recunoscută calitatea de obiect al numirii: faptul de-a-fi-om. Deci întâia etapă spre numire încadrează obiectul de numit în genul proxim (uman). Acest prim proces denominativ - nediferențiator la nivel individual - are loc, în taxonomia coșeriană, la nivelul universal al limbajului ${ }^{4}$, acolo unde lucrurile se cheamă într-un fel și nu altfel, iar locutorii le cunosc intuitiv și le acceptă denumirea printr-o convenție

1 „The identity of an individual should be considered the result of the on going interaction between the individual and his social environment. [... S Social identity has a liminal function: it is distinguishes between different individuals and position them in respect of each other" (Boerrigter 2007: 55).

2 „În acest context, numele, asemenea oricărui semn, decompozabil într-un sens cu o structură mai mult sau mai puțin motivată, personalizează (într-o mișcare de permanentă închidere spre sine) și socializează (într-o mișcare de permanentă deschidere spre alții)” (Felecan D. 2011: 64).

3 „Actul numirii nu este un act de simplă repetare a unor evenimente onomastice anterioare, ci o acțiune cu caracter novator, creator (rezultat al conlucrării dintre agenții numirii, nume, context și persoana care primește numele)" (Felecan O. 2011: 59).

4 Coșeriu (1992-1993: 135-136) identifică ,trei planuri ale structurii generale a limbajului: planul universal al vorbirii în general (independent de determinările istorice), planul istoric al limbilor și planul individual al discursului (sau al «textului»), planuri ce se evidențiază prin faptul că limbajul este o activitate umană universală care se realizează de către fiecare vorbitor în mod individual și întotdeauna potrivit cu anumite tradiții istorice (nu există vorbire în afara unei limbi)”. 
general împărtășită $[. .$.$] Numirea se suprapune aici peste desemnare, iar concordanța$ dintre lingvistic și extralingvistic se evaluează în termeni de congruență”.

Prenumele nu este un simplu semn lingvistic ${ }^{5}$, ci este purtător de o mare încărcătură afectivă, de un conținut ideologic, de o semnificație socială. Pentru antici, alegerea numelui de botez a constituit un moment de o importanță capitală, fiindcă prin acesta se transmiteau nou-născutului calitățile ce îl caracterizau pe parcursul vieții. În societatea actuală, mereu supusă schimbărilor, prenumele se încarcă cu o valoare socială: transmite un mesaj, asigură persoanei un rol în comunitate, definește o identitate. Pentru a conchide această reflecție asupra valorii psihologice și sociale a prenumelui, se poate afirma că numele de botez desemnează un spațiu-timp ${ }^{6}$ ideal unde individul este invitat să îl umple întruchipând proprietățile acestuia și conformându-se la imaginea emotivă în care el se reflectă. În prenume se înscrie, așadar, caracterul și funcția socială a persoanei. Lévi-Strauss (1962: 245-246) a susținut că «l'étymologie du prénom pouvait avoir une influence psychologique: chaque prénom possède, consciemment ou inconsciemment, une connotation culturelle qui imprègne l'image que les autres se font du porteur, et qui, par des cheminements subtils, peut contribuer à modeler sa personnalité de manière positive ou négative»

Potrivit lui Nicolae Felecan (2010: 83), „prenumele comportă două mari subdiviziuni: religioase și laice. La rândul lor, cele religioase pot fi calendaristice, înscrise în calendarul religios: Crăciun, Dimitrie, Vasile etc., și hagiografice, nume de sfinți: Ana, Grigore, Ioan, Maria, Nicolae; cele laice conduc la alte câteva categorii: slave - Bogdan, Radu, Vlad etc. - nume împrumutate din latină - Traian, Elena, Veturia - ori din alte limbi moderne (romanice, germanice, slave, neogreacă, maghiară etc.), nume delexicale, selectate din diverse câmpuri onomasiologice (nume de plante și flori: Brânduşa, Bujor, Crin, Lăcrimioara, Mugur etc.; nume de animale: Mioara, Păun etc.; nume comune: Doina, Doru, Luminița etc.)”. Astfel, prin funcția și semnificația lor socioculturală, antroponimele pot fi calendaristice, definite ca o categorie semantico-pragmatică de nume individuale a căror origine sau al căror uz se relaționează cu valori și practici religioase și laice (profane) -, la care se adaugă formele derivate și hipocoristicele.

De-a lungul timpului, a avut loc, potrivit Domniței Tomescu (2001b: 123-124),

5 „Numele de persoană și numele, în general, păstrează una dintre calitățile esențiale ale semnului lingvistic și anume acela de a avea un efect de sens real în mintea interlocutorilor, influențându-le mai mult sau mai puțin comportamentul comunicațional” (Corniță 2013: 35).

6 «Le nom propre est un signe linguistique désignant un référent précis, localisable dans le temps et l'espace, ne possédant ni sens ni motivation et dont la transmission et la perpétuation sont propres à la nature du référent» (Billy 1995: 142).

7 Datorită caracterului său identificator, numele propriu poate lua valori pozitive sau negative, valori care însoțesc ființele. Se produce astfel o fuziune între individ și numele său, făcând ca acest nume să se încarce de o evocare simbolică, chiar în punctul în care el poate lua o valoare calitativă: „dire d'une femme: «c'est une véritable Vénus!» c'est lui attribuer la qualification qui évoque l'idéal de la beauté; dire d'un jeune politicien «voilà, notre nouveau Bonaparte!», c'est lui attribuer la qualification qui évoque l'ambition, le talent politique et militaire, et un destin de grandeur" (Charaudeau 1992: 25). 
o modernizare a inventarului de prenume, importul de forme din afara sistemului tradițional s-a realizat pe mai multe căi, în etape diferite. După ce, timp de mai multe secole, alegerea prenumelui s-a făcut dintr-un inventar stabil de forme religioase și laice impuse de tradiția românească, la mijlocul secolului al XVIII-lea și începutul secolului al XIX-lea apar numeroase prenume străine, introduse în denominația românească în urma unor influențe socioculturale diverse: neogrecești, mai ales în Țara Românească, latiniste în Ardeal. Laicizarea antroponimiei se manifestă nu numai prin eliminarea unor nume și înlocuirea lor cu altele, fără nicio legătură cu creștinismul, ci și prin renunțarea la factorul religios în alegerea numelor. Această primă etapă a modernizării inventarului de prenume este urmată, la jumătatea secolului al XIX-lea, de un import consistent de forme onomastice occidentale, continuat, cu intensități diferite, până în prezent ${ }^{8}$. Conform lui Oliviu Felecan (2011: 397), „alegerea numelor de botez are două motivații, ambele subiective: pe de o parte, există un substrat afectiv, dobândit pe parcursul experienței individuale, iar, pe de altă parte, apare o influență externă, ce are ca element hotărâtor factorul social și care se manifestă sincronic în funcție de anumite evenimente colective sau de modă”.

Indiferent de originea lui, prenumele este o „vitrină” socială care oferă numeroase informații. S-a dovedit faptul că mediul social influențează alegerea celor care dau nume copiilor: «il est manifeste que, selon le milieu social d'appartenance, nous ne donnons pas le même prénom à nos enfants. En outre, attention à ne pas se fourvoyer socialement en attribuant un prénom qui n'est pas adéquat au milieu social d'appartenance de l'enfant. Il est là pour traduire une catégorie sociale à laquelle nous n'appartenons pas, notamment lorsque nous sommes enfants (cela peut survenir avec la réussite scolaire ou professionnelle mais cela prend du temps)» (Guéguen 2008: 18-19).

\subsection{Diminutivele și hipocoristicele}

Diminutivele sunt, conform DȘL (2005: 180), „o clasă de sufixe lexicale care, atașate la substantive, adjective și, foarte rar, la pronume/adverbe dau naștere la aceleași părți de vorbire care exprimă în plus o micșorare a obiectului, a persoanei sau a calităţii”. Acestea prezintă în linii generale „referentul ca având dimensiuni mai mici decât referentul cuvântului de bază” (Avram 2001: 499) și se formează cu ajutorul unor sufixe specifice (-aș, -el, -ica, -ică, -işoara, -ișor, -ița, -iță, -oara, -uca, -ucu, -uică, -uşor, -uț, -uța, -uță”), iar sensul se stabilește prin opoziție cu semnificația referentului:

-aș: Andreiaș, Dumitraș, Victoraș;

-el: Bogdănel, Claudel, Costel, Ionel, Marinel;

-ica: Angelica, Florica, Ionica, Marica, Rodica, Vasilica;

\footnotetext{
8 Caracteristicile modei antroponimice actuale românești maramureșene prezintă două tendințe principale:

1. „Interesul pentru numele străine;

2. Înmulțirea cuvintelor care alcătuiesc numele individual este o manifestare a îndepărtării de ceea ce tradiția impusese în onomastica românească, și anume: prenumele format dintr-un singur cuvânt" (Petrache 1998: 12).
} 
-ică: Costică, Dumitrică, Georgică, Ionică, Marinică, Mitică, Petrică, Vasilică;

-işoara: Anişoara, Petriş̧oara;

-işor: Ghițişor, Petrişor;

-ița: Dochiţa, Ionița, Victorița;

-iță: Gheorghiță, Ioniţă, Mihăiță;

-oara: Mărioara;

-uca: Dănuca, Irinuca, Măriuca;

-ucu: Răducu, Sănducu;

-uică: Fănuică, Răduică;

-uşor: Nicușor;

-uț: Andreiuț, Vlăduț;

-uța: Anuța, Dănuța, Elenuța, Lenuța, Pălăguța, Petruța;

-uță: Iliuță, Păvăluță.

În contextul actual al evaluării diminutivelor, se constată o receptare ambivalentă a acestora. Astfel, percepțiile divergente asupra acestor structuri lingvistice concentrează dezbaterea între doi poli: o respingere a lor, fiind considerate infantile, încifrând nivelul educativ al locutorului, și o abordare pozitivă, potrivit căreia utilizarea diminutivelor trebuie pusă pe seama limbajului afectiv, prin intermediul căruia se arată apropierea, nevoia de a exprima sentimente față de interlocutor și de a pune pe seama acestuia propriile emoții.

Potrivit lui Ionescu (1989: 144), hipocoristicele reprezintă „o formă secundară cu caracter afectiv, rezultată din modificarea formală a unui antroponim (prenume)". Acestea se formează prin procedee fonetice: scurtare (afereză: Culiță < Niculiță; sincopă: Costa < Constantin; apocopă: Gheo), redublare silabică: Lili < Elena, Mimi < Maria și lexicale: sufixare (diminutivală: Gheorghiță). Deosebirea cea mai importantă între diminutive și hipocoristice este, conform lui Graur (Ibidem: 57), „cea de formaţie: hipocoristicele se formează prin scurtare, iar diminutivele prin lungire". Atât pentru Ionescu (1989), cât şi pentru Tomescu (2001a), hipocoristicele includ formele derivate prin sufixarea numelui surs ${ }^{9}$. Afectivitatea acestor forme explică uzul lor familial, intim, mai ales în sistemul denominativ popular.

Se poate observa că aceste forme influențează personalitatea și întreaga dezvoltare a persoanei în cauză (la nivel subliminal), dar mai ales felul în care este percepută de grupurile sociale din care face parte. Atât numele de botez, cât și diminutivele sau hipocoristicele, își pun amprenta asupra dezvoltării cognitiv-emoționale a ființei.

\section{Nume laice / nume monahale: distincții și intersecții}

Identificarea unei persoane se realizează prin intemediul numelui primit în cadrul ritual ${ }^{10}$ al botezului. Acest prenume influențează viața nou-născutului, deoarece

9 „Hipocoristicele se formează cel mai adesea cu ajutorul unui sufix diminutival, de exemplu -aș, -el, -ica/-icăa, -ița/-iță, -uț/-uța, atașat fie la numele sursă fie la forma trunchiată a numelui sursă” (Tomescu 2001a: 254).

10 «Dans certaines sociétés humaines, les prénoms sont déterminés par des rituels 
copilul dobândește o identitate creștină și leagă prin botez o relație specială, unică cu Dumnezeu. În urma acestui act religios, fiecare persoană devine ființă a lui Dumnezeu, primind înfățișarea lui Hristos și având ca liant între el și divinitate numele sfântului primit, purtător de amprentă duhovnicească. „Sfântul este pildă a unirii personale cu Dumnezeu și, prin aceasta, desăvârșește taina numelui. De aceea, creștinii poartă numele sfinților și caută să urmeze în desăvârșire prietenilor Mirelui, primind ajutorul acestora prin mijlocirile lor către Dumnezeu" (Stăniloae 1978: 50, apud Petrache 1998: 6).

Caracterul religios sau laic al prenumelor are în vedere, afirmă Tomescu (2001: 112), „proveniența numelor din surse religioase sau laice și nu distribuția lor în mediul clerical sau mirean”. Însă, în comparație cu cele laice (create pe teren românesc sau împrumutate), sub influența culturii bisericești, numele monastice „are a devotional names because they refer to the one hand to God and to the people's gratitude and love for Him, and on the other hand they allude to saints, names or characters of the calendar that the mediator's role between God and human kind" (Felecan O. 2010: 204). Dacă prenumele laice (Lăcrimioara, Mioara) sunt atribuite doar mirenilor, cele cu conotație religioasă sunt prezente în ambele comunități. Deosebirea constă în faptul că prenumele religioase pot apărea în lumea laică și sub forme derivate sau hipocoristice (Gheorghiță, Ghiță), pe când în mediul monahal sunt întâlnite doar forme primare ale numelor (Filofteia, Iustin).

În ambele comunități, numele este cheia ${ }^{11}$ persoanei. Între sufletul omului și numele acestuia există o strânsă legătură, deoarece în nume este prezentă personalitatea ființei și acesta dezvăluie taina persoanei ${ }^{12}$. Pronunțarea prenumelor în mintea noastră dă naștere unei stări psihice ${ }^{13}$, stare ce va genera noi conținuturi legate de intenția de comunicare a acestuia.

d'attribution ne dépendant absolument pas du choix des parents. Le prénom est attribué selon le jour de naissance dans le mois, la semaine ou en fonction d'un paramètre extérieur (un événement quelconque survenu). Or, dans ces sociétés, ce jour n'est pas considéré comme un hasard puisque les membres de la communauté y attrribuent un sens particulier. On peut dès lors se demander si l'enfant a plus de probabilités de se conformer à ce modèle déterministe ou si, au contraire, la personnalité prend le pas sur tout acela» (Guéguen 2008: 103).

11 «Aucun nom ne naît ex nihilo: les noms disent leur ancrage ethnique, religieux, socioéconomique, culturel etc.» (vezi Vaxelaire 2005: 790, apud O. Felecan 2013: 133).

12 «'étymologie du nom est également essentielle. Ainsi, celui qui porte le nom de l'ours possède la force de l'ours ou entre dans une relation particulière avec cet animal. Le sens dont nous parlent les ethnologues relève de ce qu'on pourrait nommer un sens magique et qui n'est pas recevable d'un point de vue scientifique» (Vaxelaire 2010: 3).

13 «Avec des mesures externes de l'appréciation des prénoms, on confirme le liel observé précédemment entre désirabilité du prénom et certaines caractéristiques de la personnalité. L'effet sur la solitude est d'autant plus révélateur. En effet, la désirabilité sociale du prénom pourrait induire des préférences sociales des individus. Ceux ayant des prénoms appréciés auraient ainsi plus de renforcements sociaux positifs (plus de contacts, plus d'invitations, plus de relations...) ce qui, de fait, induirait une diminution du sentiment de solitude. Pour ceux ayant un 
Cunoscând numele unei persoane, dobândești în timp puterea de a-i descoperi adâncurile ființei și de a lega o relație cu aceasta. De aceea, afirmă Ware (2003: 34-35), „misteriosul trimis care luptă cu Iacov la vadul Laborului refuză să-și dezvăluie numele (Facerea 17:5) sau cum Iacov devine Israel (Facerea 32: 28). În același fel, Saul devine după convertirea lui, Pavel (Fapte 13: 9), iar unui călugăr, la tundere, i se dă un nume nou, ca semn al radicalei înnoiri la care s-a angajat”.

Procedeul de numire este diferit în cele două lumi. În lumea laică, prenumele este ales de către părinți, rude sau nași, spre deosebire de mediul monahal, în care viitorului călugăr, episcopul, starețul sau duhovnicul îi decide numele, novicele având siguranța că „numele consacrat va fi identic cu al unui sfânt” (Felecan, O. 2008: 98). Conform lui Petrache (1998: 5-6), „puterea și slava lui Dumnezeu sunt prezente și lucrătoare în Numele Lui, cu condiția de a fi pomenit cu trezvie: Și tot cel ce va chema numele Domnului se va mântui (Fapte 2: 21)”. Fără această participare și conștientizare, numele rămâne o simplă etichetă cu rol de identificare. Prenumele laice sunt mereu supuse modernizării, în comparație cu cele monahale care sunt finite și întotdeauna motivate prin referirea religioasă la care fac trimitere. Prenumele monahale întâlnite în mănăstirile și schiturile ortodoxe din Maramureș sunt, potrivit lui Macarie Motogna (2015): Agaton, Agnia, Ambrozie, Arsenie, Atanasie, Celest, Cleopa, Cleopatra, Efrem, Emanuela, Emanuil, Eufrasia, Eufrasie, Filofteia, Gherontie, Ieronim, Ieronima, Ilarie, Ilaria, Ilarion, Ioanichia, Ioil, Iorest, Iustin, Iustina, Macarie, Maria Magdalena, Marina, Mihai(l), Nestor, Paisie, Pimen, Sebastian, Serafim, Sofronie, Tatiana, Teoctist, Teoctista, Teofan, Teofana, Teofil, Timotei, Varahil, Varlaam, Vicenția, Vitalie.

În mediul laic maramureșean se observă evitarea (în ultimul timp) prenumelor românești tradiționale în favoarea formelor diminutivale și hipocoristice: Ancuța, Angelica, Anuța, Argentica, Dănuț, Domniţa, Ionița, Ionuc, Lenuţa, Marinel, Vasilică etc. Aceste transformări din antroponimia românească, potrivit lui Petrache (1998: 12), „reflectă evoluția interioară şi socială a omului acestui timp. Se vădește o înstrăinare progresivă de sine, pentru că numele tind să nu mai dezvăluie taina persoanei, funcționând ca simple etichete”. Spre deosebire de prenumele din mediul laic, „monastic names are not plain labels for identification purposes as they don't lose their signification. Although they may not be understood from an etymological perspective, not even by the holders, or their original meaning is not familiar to lay individuals, the spiritual attributes are overwhelmingly important for those who bear the names" (Felecan, O. 2010: 196).

\section{Profan / sacru în lumea laică și în cea monahală}

Sacrul este definit în Enciclopedia Larousse (2008) ca fiind «un fait, observable et

prénom moins apprécié, une baisse de ces renfocements sociaux aurait lieu, induisant plus de solitude. Or, ces renforcements sociaux ont un impact sur la nature des relations sociales que j’ai avec les autres et la façon dont je me perçois et dont je pense que les autres me perçoivent. Il n'est donc pas étonnant de trouver un lien commun entre désirabilité sociale d'un prénom jugement sur soi et niveau de solitude perçue» (Guéguen 2008: 75-76). 
analysable. C'est une réalité double: il est le lieu où réside une force efficace, manifestation d'une puissance divine, d'une énergie créatrice que l'homme ne comprend pas et qu'il craint parce qu'elle lui reste cachée; et un phénomène que définissent les pratiques et les rites par lesquels, justement, l'homme tâche de se rendre favorables les dieux (le dieu) ou d'éviter, au moins, qu'ils ne lui soient hostiles». Potrivit Dicționarului explicativ al limbii române, sacrul este „cu caracter religios; privitor la religie, care aparține religiei, sfânt”.

Pentru credința religioasă, sacrul este o mărturie a existenței divine, o revelație a lui Dumnezeu. Această arătare simbolică se remarcă în marile taine ale bisericii. „Sacrul apare astfel ca o categorie a sensibilităţii. La drept vorbind, este categoria pe care se reazămă atitudinea religioasă, aceea care-i dă caracterul specific, care-i impune credinciosului un sentiment de respect aparte, care-i imunizează credința împotriva spiritului de examen, o sustrage discuției, o plasează în afara rațiunii şi dincolo de ea" (Caillois 2006: 20).

În viziunea lui Eliade (1959: 73-74), schimbarea numelui în urma unei ceremonii de inițiere este o tradiție arhaică universal răspândită. Sacralizarea prin botez este modalitatea creștinismului de a consacra viața. În cadrul acestui act ritual creștin, omul vechi moare şi renaște ca ființă nouă, datorită contactului cu apa sacră. Sfântul Pavel exprimă dinamismul acestei permanente transformări lăuntrice în următorii termeni: „să vă dezbrăcați de viețuirea voastră de mai înainte, de omul cel vechi și să vă înnoiţi în duhul minții voastre, și să vă îmbrăcați în omul cel nou, cel după Dumnezeu, zidit întru dreptate și în sfințenia adevărului” (Efes 4: 22-24). Se observă că prezența sacrului în lume se manifestă prin intermediul hierofaniilor, acte care îl fac pe creștin să fie mereu preocupat de renaștere spirituală.

Potrivit lui Caillois (2006: 41), „sacrul îi suscită credinciosului aceleaşi sentimente precum focul copilului: aceeași teamă de a se arde, aceeași dorință de a-l aprinde; aceeași emoție în fața lucrului prohibit, aceeași credință despre cucerirea lui, că aduce forță și prestigiu - ori rană și moarte în caz de eșec. Iar cum focul produce deopotrivă binele și răul, sacrul desfășoară o acțiune fastă sau nefastă și primește calificările opuse de pur și de impur, de sfințenie și de sacrilegiu, ce definesc cu limitele proprii frontierele înseși ale întinderii lumii religioase”. Conform teoriei lui Eliade (2007), se pot distinge două tipuri umane: omul religios (homo religiosus) și omul areligios. Pentru omul religios lumea întreagă se identifică cu sacrul, fiindcă își asumă o existență teocentrică, în comparație cu omul areligios, care își fundamentează viaţa pe o perspectivă antropocentrică. „Oricare ar fi contextul istoric în care se încadrează, homo religiosus crede întotdeauna în existența unei realități absolute, sacrul, care transcede această lume, unde totuşi se manifestă, sanctificând-o și făcând-o reală. Homo religiosus crede că originea vieții este sacră și că existența umană își actualizează toate potențele în măsura în care este religioasă, adică în măsura în care participă la realitate" (Ibidem: 153).

Potrivit tradiţiei creștine, sacralitatea este plasată între divinitate și omul care caută sfințenia. În creștinism, sacrul se întemeiază în persoana lui lisus Hristos, întreaga creație fiind o manifestare a divinului, o arătare a lui Dumnezeu. Astfel, se poate explica 
de ce în mediul monahal (un spațiu „închis”), numele diminutivate sunt percepute ca nepotrivite cu ideea de consacrare, de religiozitate. Monahii consideră că orice diminutiv sau apelativ folosit „cioplește” sacralitatea și noblețea numelui. Pentru exemplificare, am ales mărturiile unor călugări ortodocși din Maramureș:

„Omul nu poate fi pe jumătate, pentru că numele primit este întreg. Nu se folosesc jumătăți de nume, deoarece odată ce primește haina monahală, omul vechi moare, pierzându-şi numele, și se naște omul în duh primind un nume întreg. Pe acesta nu-1 poți micşora, fiindcă i-ai fura din importanță” (Casian Filip, ecleziast al Catedralei Episcopale Sfânta Treime, Baia Mare).

„Folosirea numelui întreg arată respectul față de divinitate și față de omul cel nou născut în duh. Numele monahal definește o stare, trăirea în Duhul Sfânt. Nu poți diminua numele primit de la Dumnezeu" (Maica Tatiana, Schitul Schimbarea la Față Baia Mare).

„Călugărul este înger în trup, un miracol. Numele primit la botezul monahal îi luminează ființa. Nu poți să micșorezi această strălucire. Ți-ai pierde o parte din tine, n-ai mai fi întreg" (Motogna Macarie, stareț al Mănăstirii Sfânta Ana Rohia).

Aceste mărturisiri pot fi explicate prin raportare la semnificația numelor monahale. Interpretarea acestora justifică cuvintele călugărilor. Prenumele folosite de monahi sunt cu preponderență hagiografice, iar înțelesul lor interzice diminuarea încărcăturii spirituale și îndepărtarea de divinitate prin diminutivare.

În schimb, în spațiul laic, sacralitatea transpare și în prenumele diminutivate, nominatorul raportându-se în actul numirii la sacru și conferind prenumelui o încărcătură spirituală. Apariția sufixelor diminutivale este pusă în lumea mirenilor pe seama limbajului afectiv și corespunde nevoilor de a exprima sentimente, de a arăta apropierea faţă de interlocutor, sistemul cognitiv al locutorilor punându-și amprenta asupra limbajului utilizat. La origine, formele diminutivale reprezintă creații spontane, datorate vorbirii expresive sau celei familiare și sunt constituite plecându-se de la o bază lexicală deja existentă în limbă. Se admite, potrivit lui Iordan (1975: 166), „că orice formație diminutivală este aptă să exprime toate nuanțele legate de natura unui diminutiv, întocmai ca un instrument muzical, din care executantul poate scoate orice notă dorește (potrivit stării sale sufletești)”.

\section{Concluzii}

Se constată că modalitățile de numire în cele două lumi sunt diferite. Dacă prenumele laice sunt atribuite doar mirenilor, cele cu conotaţie religioasă sunt prezente în ambele comunități. Deosebirea constă în faptul că prenumele religioase pot apărea în lumea laică și sub forme derivate sau hipocoristice, pe când în mediul monahal sunt întâlnite doar forme primare ale numelor. În acest spațiu „închis”, numele diminutivate sunt percepute ca nepotrivite cu ideea de consacrare, de religiozitate. În schimb, în spațiul laic, sacralitatea transpare și în prenumele diminutivate, nominatorul 
raportându-se în actul numirii la sacru și conferind prenumelui o încărcătură spirituală. În lumea călugărilor, conceptul de sacru se identifică cu Dumnezeu, motiv pentru care aceștia sunt mai conservatori și în ceea ce privește actul numirii. În lumea laicilor, sacrul este înțeles ca fiind o entitate supranaturală, la care ființele se raportează. Astfel, prenumele primit este încărcat de sacru, iar diminutivarea acestuia nu împiedică manifestarea sacralității și dobândirea statutului sacerdotal al numitului.

\section{Bibliografie}

*** 2012. Dicționarul explicativ al limbii române, București: Editura Univers Enciclopedic Gold. Avram, M. 2001. Gramatica pentru toți, Ediția a III-a. Bucureşti: Editura Humanitas.

Biblia sau Sfânta Scriptură. 1975. București: Editura Institutului Biblic și de Misiune al Bisericii Ortodoxe Române.

Bidu-Vrănceanu, A., C. Călăraşu, L. Ionescu-Ruxăndoiu, M. Mancaş, G. Pană Dindelegan. 2005. Dicționar de ştiințe ale limbii (DŞL). Bucureşti: Editura Nemira.

Billy, P-H. 1995. Pour une rédéfinition du nom propre. În Nom propre et nomination - Actes du colloque de Brest, 21-24 avril 1994, M. Noaily (éd.), 75-83, Paris.

Caillois, R. 2006. Omul și sacru, Ediția a II-a revizuită. Dan Petrescu (trad.). București: Editura Nemira \& Co.

Charaudeau, P. 1992. Grammaire du sens et de l'expression. Paris: Hachette.

Corniță, G. 2013. Stilistica numelui și a numirii. Un punct de vedere. În Name and Naming: Proceedings of the Second International Conference on Onomastics: Onomastic in Contemporary Public Space: Baia Mare, May 9-11, 2013, O. Felecan (ed.), 35-43. Cluj-Napoca: Editura Mega și Editura Argonaut.

Coșeriu, E. 1992-1993. Prelegeri și conferințe (1992-1993), supliment al publicației Anuar de lingvistică și istorie literară, T. XXXIII, Seria A, Lingvistică, Institutul de Filologie Română "A. Philippide”, Iași.

Eliade, M. 2007. Sacrul și profanul, Ediția a II-a. Brândușa Prelipceanu (trad.). București: Editura Humanitas.

Felecan, D. 2011. O categorie de apelative neconvenționale recente: numele comune atribuite persoanelor feminine din domeniul showbizului românesc. În Actele Conferinței Internaționale de Onomastică Numele și numirea. Ediția I: Interferențe Multietnice în Antroponimie, Baia Mare, 19-21 septembrie 2011, O. Felecan (ed.), 235-249. Cluj-Napoca: Editura Mega.

Felecan, D. 2013. Antroponimia formelor de numire neconvenționale-perspectivă lingvistică și culturală. În Proceedings of the Second International Conference on Onomastics Name and Naming: Onomastic in Contemporary Public Space: Baia Mare, May 9-11, 2013, O. Felecan (ed.), 756-766. Cluj-Napoca: Editura Mega, Argonaut.

Felecan, N. 2010. Categoriile antroponimice: nume, supranume, poreclă. În Onomasticon. Studii despre nume şi numire I, O. Felecan (ed.), 81-121. Cluj- Napoca: Editura Mega.

Felecan, O. 2008. Un excurs antroponimic în monahismul ortodox maramureșean. În Omagiu Părintelui profesor octogenar Ilie Moldovan, 155-168. Baia Mare: Editura Universității de Nord.

Felecan, O. 2010. The Monastic Names in the North-West of Transylvania. A sociolinguistic and Cultural Perspective. Transylvanian Review XIX, Supplement nr. 3, Aspect of confessional diversity within the Romanian Space: 193-208.

Felecan, O. 2011. Prenumele țigănești: între antroponimie și nume de branduri. În Actele 
Conferinței Internaționale de Onomastică Numele și numirea. Ediția I: Interferențe Multietnice in Antroponimie, Baia Mare, 19-21 septembrie 2011, O. Felecan (ed.), 57-67. Cluj-Napoca, Editura Mega.

Felecan, O. 2013. Un excurs onomastic în spațiul public românesc actual. Cluj-Napoca: Editura Mega, Argonaut.

Graur, Al. 1965. Nume de persoane. Bucureşti: Editura Ştiinţifică.

Guéguen, N. 2008. Psichologie des prénoms. Pour mieux comprendre comment ils influencent notre vie. Paris: Dunod.

Ionescu, C. 1989. Hipocoristice. În Enciclopedia limbilor romanice, M. Sala (coord.), 144-145. Bucureşti: Editura Științifică și enciclopedică.

Iordan, I. 1975. Stilistica limbii române. Bucureşti: Editura Ştiinţifică.

Lévi-Strauss, Cl. 1962. La pensée sauvage. Paris: Plon.

Motogna, M. 2015. Chivote ale credinței: mănăstirile și schiturile din Eparhia Maramureșului și Sătmarului. Baia Mare: Editura Episcopiei Ortodoxe Române a Maramureșului și Sătmarului.

Petrache, T. 1998. Dicționar enciclopedic al numelor de botez. București: Editura Anastasia.

Sala, M. (coord.) 1989. Enciclopedia limbilor romanice. Bucureşti: Editura Știinţifică și enciclopedică.

Sala, M. 2006. De la latină la română, Ediția a II-a revăzută. București: Editura Univers Enciclopedic.

Stăniloae, D. 1978. Teologia Dogmatică Ortodoxă, Vol. III, 50-53. București: Editura Institutului Biblic și de Misiune al Bisericii Ortodoxe Române.

Tomescu, D. 2001a. Gramatica numelor proprii în limba română. București: Editura All Educațional.

Tomescu, D. 2001b. Numele de persoană la români. Perspectivă istorică. București: Editura Univers Enciclopedic.

Vaxelaire, J.-L. 2005. Les Noms Propres. Une analyse lexicologique et historique. Paris: Honoré Champion.

Vaxelaire, J.-L. 2010. Étymologie, signification et sens des noms propres. Texto!, Juillet. http:// www.revue-texto.net/index.php?id=2649 (accesat în 02 februarie 2013).

Ware, K. 2003. Puterea numelui. Rugăciunea lui Iisus în spiritualitatea ortodoxă. București: Editura Christiana.

Zafiu, R. 2010. Evaluarea diminutivelor. În Studii de limba română. Omagiu profesorului Grigore Brâncuş, Gheorghe Chivu, Oana Uță Bărbulescu (ed.), 291-297. Bucureşti: Editura Universității din Bucureşti.

Zafiu, R. 2011. Diminutivele în româna actuală: lexicalizare și utilizare pragmatică. În Studii de lingvistică. Omagiu doamnei profesoare Angela Bidu-Vrănceanu, Isabela Nedelcu, Al. Nicolae, Alice Toma, Rodica Zafiu (ed.), 373-382. Bucureşti: Editura Universității din Bucureşti.

http://www.larousse.fr/encyclopedie/divers/sacr\%C3\%A9/89590 